REVIEW ARTICLE

\title{
Review of the Effect of Religion on Anxiety
}

\section{William C Stewart, MD*, Megan J Wetselaar, BA, Lindsay A Nelson, BS and Jeanette A Stewart, RN}

Teleios, Inc., Charleston, South Carolina, USA

*Corresponding author: William C Stewart, MD, Teleios, Inc., Charleston, South Carolina, USA, Tel: 843-606-0776, Fax: 888-808-9564

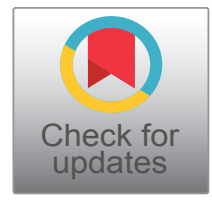

\begin{abstract}
Background: Very little information is available about the influence of religion upon anxiety. The objective of this article is to review the medical literature regarding the influence of personal religious belief and religious-based activities on anxiety.
\end{abstract}

Methods: Studies were reviewed evaluating anxiety and the effect of religion in peer reviewed medical literature by using search terms in PubMed and Cochrane data bases.

Results: There were 32 studies included. This review showed, in almost every study, that religion in general, religious training, spirituality, faith, prayer, religious community and worship were associated with reduced anxiety (stress). These effects were observed in both healthy individuals and in various patient populations. In addition, a number of studies demonstrated that religious based treatment intervention was helpful in the treatment of anxiety.

Conclusion: This review suggests that religious practice and belief may assist individuals suffering with anxiety.

\section{Keywords}

Anxiety, Stress, Well-being, Wellbeing, Religion, Spirituality

\section{Introduction}

Anxiety is a very common condition in first world countries and is often defined as intense, excessive and persistent worry and fear about everyday situations [1]. Further, this condition is associated with a higher incidence of depression, suicide and substance abuse [2-4].

Fortunately, pharmaceutical treatments are available for anxiety as well as non-pharmaceutical based therapy such as: Herbals, meditation, yoga, psychological counseling, exercise, refraining from drugs/alcohol and maintaining healthy sleep habits [5-7].
In addition, religious-based personal and social activities have been shown to alleviate stress and anxiety [8-11]. However, in some cases perceived adverse experiences with God have increased anxiety [12,13].

Very little information is available which reviews the influence of religion upon anxiety. The purpose of this article is to review the medical literature regarding the influence of personal religious belief and religious-based activities on anxiety. The authors hope this review will provide a summary of the influence of religion on this unfortunate condition as well as suggest future avenues of research.

\section{Methods}

We reviewed articles evaluating the influence of religion on anxiety (or stress) in peer-reviewed medical literature. We included English language articles. The following terms or combination of terms were searched: Anxiety (treatment of, to treat, therapy), stress, spirituality religion, religious, Christianity, spirituality, faith, God, Muslims, Buddhism, Confucianism, Hinduism, prayer and peace.

Trial designs included both prospective longitudinal and cross-sectional clinical trial designs. All subjects of any age, race, religion and geographic ranges were allowed. Article populations were assumed Christians in countries traditionally holding to this faith when religion was not identified.

\section{There were no specific exclusion criteria.}

The study was performed using PubMed (http://www. ncbi.nlm.nih.gov/pubmed/) and Cochrane (http://www. cochranelibrary.com/) to search the published medical literature. A database was made from the collected articles. 
The following information was abstracted from each article: Citation, population, country, study groups, methods (i.e., survey, interview, and questionnaire), and number of subjects, primary variable, results, conclusions, and link to the article.

Seventy articles were chosen for initial review. Of these 38 were excluded because they did not fit the inclusion criteria (i.e., not in English, religion not a main parameter, review design). All studies noted in this article were performed by self-reported questionnaires or surveys, uncontrolled, and cross-sectional unless otherwise stated.

\section{Results}

In total, 32 articles met the inclusion criteria for the review. Of these 26 noted a positive relationship with God reduced anxiety. In contrast, three articles showed that a negative relationship with God produced worsening anxiety, and three noted no relationship effects on anxiety. No articles found that a positive relationship with God worsened anxiety.

\section{General anxiety and depression}

Allen and coworkers questioned 73 adult US male inmates and found among older inmates that their emotional health, levels of anxiety and depression were positively affected by God and religious experiences [14]. Papazisis and associates evaluated 123 Greek nursing students and showed that religion can be helpful in lowering depression, stress and anxiety [15]. Mann and coworkers evaluated 344 pregnant American women and showed religiosity and spirituality were associated with reduced anxiety [16].

In non-Christian populations the effects of religion on anxiety were also observed. Vasegh \& Mohammadi surveyed 285 medical students in Iran and discovered religion can offer protection against anxiety and depression [17]. Rungreangkulkij \& Wongtakee evaluated 21 patients suffering from symptoms of anxiety in Thailand and showed counseling with Buddhist principles could potentially benefit patients with emotional anxiety-based problems [18].

\section{Prayer and Christian community intervention}

Tloczynski \& Fritzsch studied 8 US undergrads and discovered that others' prayers lowered anxiety scores. The reduced anxiety scores somewhat matched the timing for which they received prayer. In contrast, those not receiving prayer did not have decreased anxiety scores [19]. Boelens and associates evaluated 44 subjects with depression or anxiety who received six weekly 1 -hour prayer sessions by direct person-to-person prayer contact versus control [20]. The study showed, both one month later and one year later, significantly less depression and anxiety, increased optimism, and greater levels of spiritual experience than did the pre-prayer baseline. O'Laoire surveyed 406 participants who received daily interventional prayer by three agents for 12 weeks and discovered, compared to baseline, improved anxiety levels [21]. Graham \& Roemer questioned 50 African Americans and found that church-based social support alleviated racial anxiety [22].

\section{Religious based treatment}

A number of studies have evaluated various treatment programs designed to be, at least in part, religiously based. These programs in general have benefited anxiety. Bowland and coworkers evaluated 43 adult US female survivors of interpersonal trauma using an 11-session, spiritually focused intervention [23]. The results showed a strong benefit for the spiritually focused group intervention in older women trauma survivors. The women in the treatment group had significantly lower depressive symptoms, anxiety and physical symptoms when compared to the control group. These therapeutic gains were still present three months later.

Stanley and coworkers questioned 66 American adults in primary care cognitive-behavioral therapy for late-life anxiety and/or depression and found for Christians receiving counseling, a religious and/ or spiritual basis was very important [24]. Koszycki and associates evaluated 18 Canadian patients who suffered from at least moderate anxiety and assigned them randomly to either 12 sessions of spiritually based intervention or cognitive-behavioral therapy [25]. The study showed that multi-faith spiritually based interventions were effective treatments for general anxiety disorder (GAD) maintained at least up to six months following intervention.

In another similar study, Koszycki and associates studied 23 Canadian participants with GAD of at least moderate severity [26]. The participants were assigned to 12 sessions of either spiritual-based intervention or supportive psychotherapy. They found that at three months follow up the non-denominational spiritual-based intervention had greater efficacy than the control supportive psychotherapy group in improving symptoms of GAD and enhancing spiritual wellbeing.

In Malaysia, a non-Christian country, Razali and coworkers studied and surveyed 203 religious patients (103 with anxiety and 100 with depression) [27]. The first treatment group received standard care and the study group, along with receiving standard care, was given religious-sociocultural psychotherapy. The religious and sociocultural component in the treatment program helped improve anxiety and depressive symptoms in patients with strong religious and cultural backgrounds, but at the six-month follow up the differences were no longer significant. Rosmarin and associates questioned 125 US religious Jews with elevated levels of stress and worry [28]. They were treated in one of three groups: A spiritually integra- 
ted treatment program, progressive muscle relaxation, or non-active control. The authors found greater benefits amongst the spiritually integrated treatment program participants with improved stress, worry, depression and intolerance of uncertainty than within the control.

\section{Death anxiety}

Henrie \& Patrick used data of 635 US adults and found religiousness was inversely associated, while religious doubt was positively associated, with death anxiety [29]. Hui \& Fung surveyed 133 Christian Chinese university students in the United Kingdom and discovered that intrinsic-but not extrinsic-motivated religiosity lowered anxiety toward death and dying, either of oneself or someone close, by giving perceived purpose in life [30].

In non-Christian lands, Suhail \& Akram surveyed 132 Pakistanis and discovered women, older people and those less religious were more anxious than others about different dimensions of death [31]. Daradkeh \& Moselhy evaluated 85 drug dependent Arabic males in the United Arab Emirates and showed that death anxiety was higher in drug abusers, especially if they were not practicing a religion [32].

\section{Anxiety in illness}

Various diagnoses: Johnson and associates questioned 210 US patients ( $91 \%$ were Christian) with advanced illness (1/3 each with cancer, chronic obstructive pulmonary disorder and congestive heart failure) and found that negative religious experiences were associated with symptoms of anxiety and depression [33].

HIV: Steglitz and coworkers surveyed 135 rural, low-income HIV-positive adults, mostly Christian (45\%) or Muslim (35\%), in Tanzania and noted that religiosity was related to reduced avoidance coping and increased social support, which were related to reduced depression, anxiety, and stress [34]. Coleman and coworkers questioned 1071 ethnically diverse US adult HIV patients and found prayer could be beneficial to HIV patients, particularly for older African Americans, Hispanics, and females [35].

Cancer: Johnson and coworkers evaluated 10 American women receiving chemotherapy for recurrent ovarian cancer and showed that personal prayer benefited their emotional wellbeing, anxiety, depression, and faith [36]. Olver \& Dutney surveyed 999 cancer patients in Australia, using quality of life and spiritual wellbeing scales at baseline and six month follow up [37]. They discovered that intercessory prayer made small but significant improvements in these patients' wellbeing.

Janiszewska and associates questioned 180 adult women with end-stage breast cancer in Poland and found religion was an effective coping factor for an- xiety [38]. McCoubrie \& Davies evaluated 85 UK cancer patients and showed a greater sense of existential wellbeing (spirituality) was associated with lower anxiety/depression levels, while religious wellbeing and strength of belief had no impact on psychological wellbeing [39].

Schreiber questioned 130 early US breast cancer survivors and found that belief in an engaged God was significantly correlated to psychological wellbeing, decreased stress and lessened concern about recurrence of their cancer [40]. Kaczorowski questioned 114 adults diagnosed with cancer and found high levels of spirituality were associated with lower levels of anxiety [41]. Boscalgia and coworkers evaluated 100 patients with a one year cancer diagnosis from outpatient gynecological cancer clinics in Australia and found negative spiritual coping was associated with greater anxiety scores [42].

Cardiovascular disease: Hosseini and associates showed in 70 Iranian Muslim coronary artery bypass graft patients that religious training reduced anxiety in comparison with the standard care group [43]. Ai and coworkers surveyed 262 US patients who underwent open heart surgery and noted that use of preoperative prayer, as well as levels of optimism and hope, predicted lower levels of depression while subjective religiousness, marital status, and hope predicted lower levels of anxiety 30 days after surgery [44]. Bay and associates questioned 166 American coronary artery bypass graft patients both one and six months after surgery and found chaplain visits helped increase positive religious coping and decrease negative religious coping, but did not affect anxiety [45].

\section{Discussion}

This review showed, in almost every study, that religion in general, religious training, spirituality, faith, prayer, and church-based social support were associated with reduced anxiety (stress). In many instances depression was helped as well. These effects were observed in both healthy individuals and in various patient populations. In addition, a number of studies demonstrated that religious based treatment intervention directed specifically towards religious persons was helpful in the treatment of anxiety.

Furthermore, this effect was observed across different countries, cultures, healthy as well as unhealthy populations with a variety of diseases, and religions; although the great majority of studies were performed in first world historically Christian countries.

Why would religion assist anxious patients? The reasons are not known specifically from the literature, however we could speculate the following: First, the belief in the care of an almighty God taking a personal interest in a person's psychological suffering through 
such activities as prayer, worship, and religious training might give comfort and hope of a potential answer to anxiety; second, the hope of an eternal life that surpasses the suffering on this earth might also give psychological comfort; and third, socialization with others of the same faith, inside or outside a place of worship, might provide a distraction from a person's anxiety as well as a reminder of their religion's teachings.

What do these findings mean to clinicians? First, clinicians might realize that religious compared to non-religious patients may welcome another avenue of potential help. Second, the literature indicates that a program which includes religion in the evaluation and/or treatment of anxiety may provide an extra benefit. These treatment based programs generally were described as a spiritually based: Intervention, counseling, or integrated program.

Despite these positive findings much work is required to fully understand the impact of religion on the psychological makeup of an individual and its efficacy in alleviating stress. Further, these differences need to be understood across different cultures and religions. This is because past medical literature tends not to differentiate religions, or the extent of adherence to a particular religion, on the psychological impact of the individual.

In reality there are major differences between religions described in their sacred books in the described character of God, the expectations upon humans and how access to God is gained. These differences might make an important difference in a person's psychological health based on their perceived acceptance by God.

For example, Christianity assures access to God by faith alone in Christ's sacrificial death on the cross (grace). In contrast, at least one major Christian denomination and a para-Christian religion combine a mixture of grace and man's efforts (works) to reach salvation. Further, generally most para- and non-Christian religions perceive access to God by a system of works [46].

This review suggests that religious practice and belief may assist individuals suffering with anxiety. Further research will hopefully provide better understanding of religious practices across cultures to enhance how clinicians can use this important aspect of patients' lives to help treat their patients.

\section{Authorship Contribution}

Conception or design of the work- WCS, MJW; Data collection- WCS, MJW; Data analysis and interpretation- MJW, LAN; Drafting the article- WCS, LAN; Critical revision of the article- WCS, LAN; Final approval of the version to be published- WCS, MJW, LAN, JAS.

\section{References}

1. Anxiety disorders, Mayo Clinic.

2. Beesdo K, Bittner A, Pine DS, Stein MB, Höfler M, et al.
(2007) Incidence of social anxiety disorder and the consistent risk for secondary depression in the first three decades of life. Arch Gen Psychiatry 64: 903-912.

3. Gould MS, King R, Greenwald S, Fisher P, Schwab-Stone $\mathrm{M}$, et al. (1998) Psychopathology associated with suicidal ideation and attempts among children and adolescents. J Am Acad Child Adolesc Psychiatry 37: 915-923.

4. Smith JP, Book SW (2008) Anxiety and substance use disorders: A review. Psychiatr Times 25: 19-23.

5. Sarris J, Moylan S, Camfield DA, Pase MP, Mischoulon D, et al. (2012) Complementary medicine, exercise, meditation, diet, and lifestyle modification for anxiety disorders: A review of current evidence. Evid Based Complement Alternat Med 2012: 1-20.

6. Bystritsky A, Khalsa SS, Cameron ME, Schiffman J (2013) Current diagnosis and treatment of anxiety disorders. P T 38: 30-57.

7. Generalized anxiety disorder, Mayo Clinic.

8. Hamilton JB, Moore AD, Johnson KA, Koenig HG (2013) Reading the Bible for guidance, comfort, and strength during stressful life events. Nurs Res 62: 178-184.

9. Krause N (2006) Gratitude toward god, stress, and health in late life. Res Aging 28: 163-183.

10. Paukert AL, Phillips L, Cully JA, Loboprabhu SM, Lomax JW, et al. (2009) Integration of religion into cognitive-behavioral therapy for geriatric anxiety and depression. J Psychiatr Pract 15: 103-112.

11. Berry D (2002) Does religious psychotherapy improve anxiety and depression in religious adults? A review of randomized controlled studies. Int J Psychiatr Nurs Res 8: 875-890.

12. Koenig HG (2009) Research on religion, spirituality, and mental health: A review. Can J Psychiatry 54: 283-291.

13. Ano GG, Vasconcelles EB (2005) Religious coping and psychological adjustment to stress: A meta-analysis. J Clin Psychol 61: 461-480.

14. Allen RS, Phillips LL, Roff L, Cavanaugh R, Day L (2008) Religiousness/spirituality and mental health among older male inmates. Gerontologist 48: 692-697.

15. Papazisis G, Nicolaou P, Tsiga E, Christoforou T, Sapountzi-Krepia D (2014) Religious and spiritual beliefs, self-esteem, anxiety, and depression among nursing students. Nurs Health Sci 16: 232-238.

16. Mann JR, McKeown RE, Bacon J, Vesselinov R, Bush F (2008) Religiosity, spirituality and antenatal anxiety in Southern U.S. women. Arch Womens Ment Health 11: 1926.

17. Vasegh S, Mohammadi MR (2007) Religiosity, anxiety, and depression among a sample of Iranian medical students. Int J Psychiatry Med 37: 213-227.

18. Rungreangkulkij S, Wongtakee W (2008) The psychological impact of Buddhist counseling for patients suffering from symptoms of anxiety. Arch Psychiatr Nurs 22: 127-134.

19. Tloczynski J, Fritzsch S (2002) Intercessory prayer in psychological well-being: using a multiple-baseline, acrosssubjects design. Psychol Rep 91: 731-741.

20. Boelens PA, Reeves RR, Replogle WH, Koenig HG (2012) The effect of prayer on depression and anxiety: Maintenance of positive influence one year after prayer intervention. Int J Psychiatry Med 43: 85-98. 
21. O'Laoire S (1997) An experimental study of the effects of distant, intercessory prayer on self-esteem, anxiety, and depression. Altern Ther Health Med 3: 38-53.

22. Graham JR, Roemer L (2012) A preliminary study of the moderating role of church-based social support in the relationship between racist experiences and general anxiety symptoms. Cultur Divers Ethnic Minor Psychol 18: 268-276.

23. Bowland S, Edmond T, Fallot RD (2012) Evaluation of a spiritually focused intervention with older trauma survivors. Soc Work 57: 73-82.

24. Stanley MA, Bush AL, Camp ME, Jameson JP, Phillips LL, et al. (2011) Older adults' preferences for religion/spirituality in treatment for anxiety and depression. Aging Ment Health 15: 334-343.

25. Koszycki D, Raab K, Aldosary F, Bradwejn J (2010) A multifaith spiritually based intervention for generalized anxiety disorder: A pilot randomized trial. J Clin Psychol 66: 430441.

26. Koszycki D, Bilodeau C, Raab-Mayo K, Bradwejn J (2014) A multifaith spiritually based intervention versus supportive therapy for generalized anxiety disorder: A pilot randomized controlled trial. J Clin Psychol 70: 489-509.

27. Razali SM, Hasanah Cl, Aminah K, Subramaniam M (1998) Religious sociocultural psychotherapy in patients with anxiety and depression. Aust NZJ Psychiatry 32: 867-872.

28. Rosmarin $\mathrm{DH}$, Pargament $\mathrm{KI}$, Pirutinsky S, Mahoney A (2010) A randomized controlled evaluation of a spiritually integrated treatment for subclinical anxiety in the Jewish community, delivered via the Internet. J Anxiety Disord 24: 799-808.

29. Henrie J, Patrick JH (2014) Religiousness, religious doubt, and death anxiety. Int J Aging Hum Dev 78: 203-227.

30. Hui VK, Fung HH (2009) Mortality anxiety as a function of intrinsic religiosity and perceived purpose in life. Death Stud 33: 30-50.

31. Suhail K, Akram S (2002) Correlates of death anxiety in Pakistan. Death Stud 26: 39-50.

32. Daradkeh F, Moselhy HF (2011) Death anxiety (Thanatophobia) among drug dependents in an Arabic psychiatric hospital. Am J Drug Alcohol Abuse 37: 184-188.

33. Johnson KS, Tulsky JA, Hays JC, Arnold RM, Olsen MK, et al. (2011) Which domains of spirituality are associated with anxiety and depression in patients with advanced illness? J Gen Intern Med 26: 51-58.

34. Steglitz J, Ng R, Mosha JS, Kershaw T (2012) Divinity and distress: The impact of religion and spirituality on the mental health of HIV-positive adults in Tanzania. AIDS Behav 16: 2392-2398.

35. Coleman CL, Eller LS, NokesKS, Bunch E, Reynolds NR, et al. (2006) Prayer as a complementary health strategy for managing HIV-related symptoms among ethnically diverse patients. Holist Nurs Pract 20: 65-72.

36. Johnson ME, Dose AM, Pipe TB, Petersen WO, Huschka $M$, et al. (2009) Centering prayer for women receiving chemotherapy for recurrent ovarian cancer: A pilot study. Oncol Nurs Forum 36: 421-428.

37. Olver IN, Dutney A (2012) A randomized, blinded study of the impact of intercessory prayer on spiritual well-being in patients with cancer. Altern Ther Health Med 18: 18-27.

38. Janiszewska J, Buss T, de Walden-Galuszko K, Majkowicz M, Lichodziejewska-Niemierko M, et al. (2008) The religiousness as a way of coping with anxiety in women with breast cancer at different disease stages. Support Care Cancer 16: $1361-1366$.

39. McCoubrie RC, Davies AN (2006) Is there a correlation between spirituality and anxiety and depression in patients with advanced cancer? Support Care Cancer 14: 379-385.

40. Schreiber JA (2011) Image of god: Effect on coping and psychospiritual outcomes in early breast cancer survivors. Oncol Nurs Forum 38: 293-301.

41. Kaczorowski JM (1989) Spiritual well-being and anxiety in adults diagnosed with cancer. Hosp J 5: 105-116.

42. Boscalgia N, Clarke DM, Jobling TW, Quinn MA (2005) The contribution of spirituality and spiritual coping to anxiety and depression in women with a recent diagnosis of gynecological cancer. Int J Gynecol Cancer 15: 755-761.

43. Hosseini M, Salehi A, Fallahi Khoshknab M, Rokofian A, Davidson PM (2013) The effect of a preoperative spiritual/ religious intervention on anxiety in Shia Muslim patients undergoing coronary artery bypass graft surgery: A randomized controlled trial. J Holist Nurs 31: 164-172.

44. Ai AL, Ladd KL, Peterson C, Cook CA, Shearer M, et al. (2010) Long-term adjustment after surviving open heart surgery: the effect of using prayer for coping replicated in a prospective design. Gerontologist 50: 798-809.

45. Bay PS, Beckman D, Trippi J, Gunderman R, Terry C (2008) The effect of pastoral care services on anxiety, depression, hope, religious coping, and religious problem solving styles: A randomized controlled study. J Relig Health 47: 57-69.

46. Valea $E$ (2016) Salvation and eternal life in world religions.

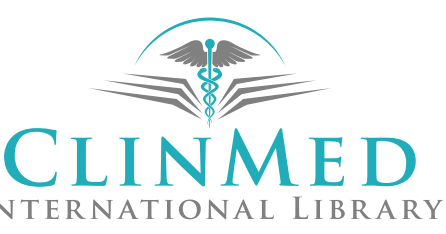

